\title{
АНАЛИЗ ПОКАЗАТЕЛЕЙ БАНКОВСКОГО КРЕДИТОВАНИЯ СУБЪЕКТОВ МАЛОГО И СРЕДНЕГО ПРЕДПРИНИМАТЕЛЬСТВА В РОССИЙСКОЙ ФЕДЕРАЦИИ
}

\author{
(ㄷ) 2020 Далбаева В.Ю. \\ кандидат экономических наук, старший преподаватель \\ Байкальский государственный университет, Россия, Иркутск \\ E-mail: dalbaeva_v@mail.ru
}

\begin{abstract}
Одной из ключевых проблем развития отечественного малого и среднего предпринимательства в настоящее время является проблема нехватки финансовых средств в связи с низкой доступностью кредитных ресурсов. С целью выявления недостатков действующей практики банковского кредитования субъектов малого и среднего предпринимательства в статье проводится анализ ее основных показателей на основе официальных данных Центрального банка Российской Федерации: динамики объемов выданных кредитов субъектам малого и среднего предпринимательства, суммы задолженности по предоставленным кредитам, а также суммы просроченной задолженности по кредитам.
\end{abstract}

Ключевые слова: Банковское кредитование, субъекты малого и среднего предпринимательства, объемы выданных кредитов, задолженность по выданным кредитам, просроченная задолженность по кредитам.

Несмотря на комплекс мер, предпринятых государством в последние годы с целью поддержки кредитования субъектов малого и среднего предпринимательства, проблема доступности финансовых ресурсов для этой категории предприятий не перестает быть актуальной. Об этом свидетельствуют результаты опроса руководителей малых предприятий, проводимого ежегодно Федеральной службой государственной статистики [1]. Так, по данным этого опроса за 2018 год среди основных факторов, ограничивающих рост производства на малых предприятиях добывающих и обрабатывающих производств, а также занятых в сфере финансового лизинга, респонденты наиболее часто указывали на ряду с «недостаточным спросом на продукцию на внутреннем рынке» и «высоким уровнем налогообложения» такие проблемы, как «сложность с получением кредита» и «недостаток финансовых средств» [1]. В связи с этим, необходимость и актуальность исследования современной практики банковского кредитования субъектов малого и среднего предпринимательства, как основного источника финансирования деятельности предприятий, не вызывает сомнений.

По данным Центрального банка Российской Федерации совокупные объемы кредитов, выданных кредитными организациями стра- ны в 2017-2019 гг., непрерывно увеличивались (табл.1).

Как видно из данных таблицы 1 , совокупный темп роста объемов выданных кредитов за 2017-2019 гг. (за 3 года) составил 166,8\% (среднегодовой темп роста $-122,2 \%)$, что является существенным.

Следует отметить, что не по всем категориям заемщиков наблюдалась однозначная динамика. Так, темп роста объемов кредитов, предоставленных юридическим лицам и индивидуальным предпринимателям, включая субъектов малого и среднего предпринимательства, за исследуемый период составил 161,0\%. Отдельно по субъектам малого и среднего предпринимательства темп роста объемов выданных кредитов составил $147,6 \%$, а по физическим лицам - 194,8\%. Следовательно, объемы кредитования субъектов малого и среднего предпринимательства росли наименьшими темпами в разрезе категорий заемщиков (и ниже совокупного темпа роста объемов кредитов), что обусловило, несмотря на меры, предпринимаемые государством, проблемы предпринимателей с привлечением финансовых ресурсов.

Выявленная отрицательная тенденция способствовала снижению удельного веса кредитов, предоставленных субъектам малого и среднего предпринимательства, в общем объеме выдан- 
Таблица 1. Динамика объемов выданных кредитов кредитными организациями Российской Федерации в 2017-2019 гг., млн. руб.*

\begin{tabular}{|l|c|c|c|c|c|c|c|c|}
\hline \multicolumn{1}{|c|}{ Показатель } & \multicolumn{2}{|c|}{01.01 .2017} & \multicolumn{2}{c|}{01.01 .2018} & \multicolumn{2}{c|}{01.01 .2019} & \multicolumn{2}{c|}{01.01 .2020} \\
\cline { 2 - 9 } & млн. руб. & $\%$ & млн. руб. & $\%$ & млн. руб. & $\%$ & млн. руб. & \% \\
\hline $\begin{array}{l}\text { 1. Объем кредитов, } \\
\text { предоставленных } \\
\text { юридическим } \\
\text { лицам-резидентам } \\
\text { и индивидуальным } \\
\text { предпринимателям, } \\
\text { в том числе } \\
\text { субъектам Мсп }\end{array}$ & 35579642 & 83,1 & 38452742 & 80,6 & 45005060 & 78,3 & 57310959 & 80,3 \\
\hline $\begin{array}{l}\text { 2. Объем кредитов, } \\
\text { предоставленных } \\
\text { физическим лицам- } \\
\text { резидентам }\end{array}$ & 7210282 & 16,9 & 9233726 & 19,4 & 12456050 & 21,7 & 14044571 & 19,7 \\
\hline Итого: & 42789924 & 100,0 & 47686468 & 100,0 & 57461110 & 100,0 & 71355530 & 100,0 \\
\hline $\begin{array}{l}\text { Темп роста к } \\
\text { 01.01.2017,\% }\end{array}$ & 100,0 & - & 111,4 & - & 134,3 & - & 166,8 & - \\
\hline
\end{tabular}

* Составлено и рассчитано автором по данным [2]

ных кредитов за 2017-2019 гг. с 12,4\% до 11,0\% (в то время как удельный вес кредитов, предоставленных физическим лицам, в совокупном кредитном портфеле увеличился с 16,9\% до 19,7\% за счет опережающих темпов роста).

Общая сумма задолженности по выданным кредитными организациями кредитам в 20172019 гг. также непрерывно увеличивалась (табл. 2).

Данные таблицы 2 свидетельствуют о том, что темпы роста общей суммы задолженности по кредитам за исследуемый период были не- сколько ниже, чем темпы роста объемов выданных кредитов за аналогичный период (за 3 года темпы роста задолженности по кредитам составили $129,9 \%)$. Это свидетельствует о преобладании краткосрочного кредитования, где большая часть кредитов погашается в течение года и, как следствие, не приводит к увеличению остатков по счетам ссудной задолженности на конец отчетного периода. Выявленный факт, на наш взгляд, нельзя характеризовать как однозначно положительный, так как, несмотря на общий рост показателей банковского кредитования,

Таблица 2. Динамика задолженности по выданным кредитам кредитными организациями Российской Федерации в 2017-2019 гг., млн. руб.*

\begin{tabular}{|c|c|c|c|c|c|c|c|c|}
\hline \multirow{2}{*}{ Показатель } & \multicolumn{2}{|c|}{01.01 .2017} & \multicolumn{2}{|c|}{01.01 .2018} & \multicolumn{2}{|c|}{01.01 .2019} & \multicolumn{2}{|c|}{01.01 .2020} \\
\hline & млн. руб. & $\%$ & млн. руб. & $\%$ & млн. руб. & $\%$ & млн. руб. & $\%$ \\
\hline $\begin{array}{l}\text { 1. Задолженность } \\
\text { по кредитам, } \\
\text { предоставленным } \\
\text { юридическим } \\
\text { лицам-резидентам } \\
\text { и индивидуальным } \\
\text { предпринимателям, } \\
\text { в том числе } \\
\text { субъектам МСП }\end{array}$ & 28204079 & 72,4 & 29219395 & 70,7 & 32228764 & 68,4 & 33056743 & 65,3 \\
\hline $\begin{array}{l}\text { 2. Задолженность } \\
\text { по кредитам, } \\
\text { предоставленным } \\
\text { физическим лицам- } \\
\text { резидентам }\end{array}$ & 10773733 & 27,6 & 12135449 & 29,3 & 14856625 & 31,6 & 17564173 & 34,7 \\
\hline Итого: & 38977812 & 100,0 & 41354844 & 100,0 & 47085389 & 100,0 & 50620916 & 100,0 \\
\hline $\begin{array}{l}\text { Темп роста к } \\
01.01 .2017, \%\end{array}$ & 100,0 & - & 106,1 & - & 120,8 & - & 129,9 & - \\
\hline
\end{tabular}

* Составлено и рассчитано автором по данным [2] 
преобладание в нем краткосрочного кредитования говорит о недостаточной уверенности и кредиторов, и заемщиков в стабильности экономической ситуации как в целом в стране, так и относительно собственной финансовой стабильности и планов на будущее.

Рост задолженности по кредитам в разрезе категорий заемщиков был в 2017-2019 гг. неравномерным. Так, наибольшими темпами росла задолженность по кредитам, предоставленным физическим лицам - 163,0\% за 3 года, что привело к увеличению удельного веса задолженности по кредитам этой категории заемщиков в совокупной сумме задолженности по кредитам с 27,6\% до 34,7\%. Динамика задолженности по кредитам, предоставленным субъектам малого и среднего предпринимательства, в анализируемом периоде были неоднозначной: после некоторого снижения суммы задолженности по итогам 2017 г., в 2018-2019 гг. наблюдался некоторый рост этого показателя. В итоге, совокупный темп роста задолженности по кредитам, предоставленным субъектам малого и среднего предпринимательства, за 3 года составил лишь $106,0 \%$, что опять же является минимальным показателем по сравнению с аналогичными показателями по другим категориям заемщиков (юридическим лицам и индивидуальным предпринимателям без учета субъектов малого и среднего предпринимательства, а также физическим лицам). Этого явно недостаточно для решения проблемы финансирования, которая остро стоит перед отечественными предпринимателями.

Важным представляется исследование динамики просроченной задолженности по кредитам (табл. 3).

Данные таблицы 3 свидетельствуют о сниже-

Таблица 3. Динамика показателей просроченной задолженности по выданным кредитам кредитными организациями Российской Федерации в 2017-2019 гг.*

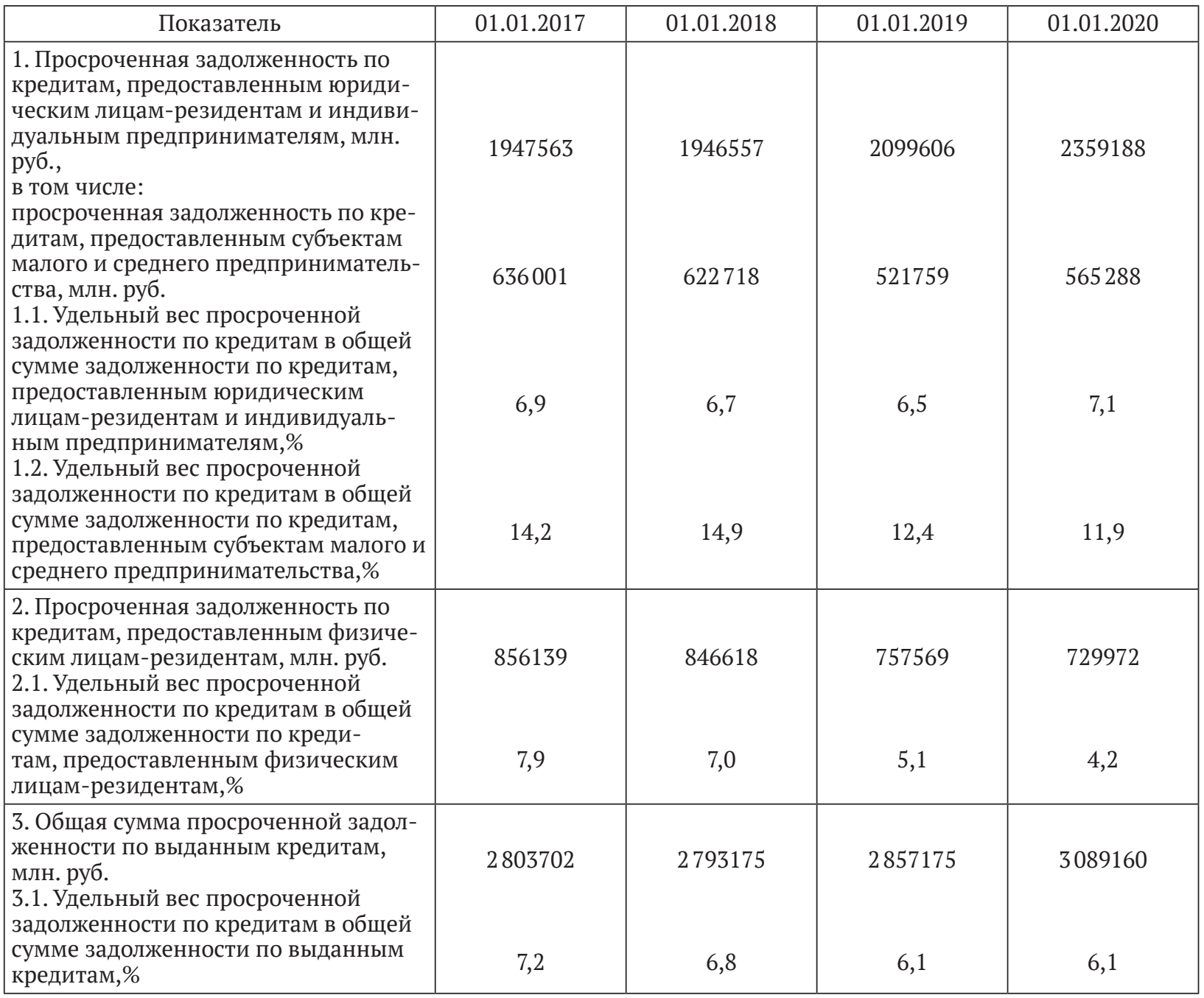

* Составлено и рассчитано автором по данным [2] 
нии удельного веса просроченной задолженности по кредитам в общей сумме задолженности по кредитам в 2017-2019 гг. с 7,2\% до 6,1\%, что говорит об улучшении качества совокупного кредитного портфеля. Но в разрезе категорий заемщиков динамика просроченной задолженности была неоднозначной. Так, качество кредитного портфеля по заемщикам - юридическим лицам и индивидуальным предпринимателям несколько снизилось в анализируемом периоде - удельный вес просроченной задолженности по кредитам в данном случае вырос с 6,9\% на 01.01.2017 до 7,1\% на 01.01.2020.

Напротив, по заемщикам - физическим лицам на фоне опережающих темпов роста объемов кредитования и суммы задолженности по кредитам этой категории заемщиков в анализируемом периоде наблюдалось значительное снижение удельного веса просроченной задолженности по кредитам с 7,9\% на 01.01.2017до 4,2\% на 01.01.2020.

Наихудшее положение по показателю просроченной задолженности наблюдается по заемщикам - субъектам малого и среднего предпринимательства. Так, несмотря на некоторое снижение суммы просроченной задолженности по кредитам, предоставленным этой категории заемщиков, ее удельный вес в общей сумме задолженности по кредитам, предоставленным субъектам малого и среднего предпринимательства, остается на очень высоком уровне, превышая аналогичный показатель по всем категориям заемщикам практически в 2 раза на протяжении всего анализируемого периода: $14,2 \%$ против 7,2\% на 01.01.2017, 11,9\% против 6,1\% на 01.01.2020.

Субъекты малого и среднего предпринимательства в качестве заемщиков традиционно являются для банков наиболее рискованным сегментом в силу известных причин, связанных со спецификой их финансово-хозяйственной деятельности. Этим объясняется нежелания многих банков кредитовать этот клиентский сегмент. Столь высокий уровень просроченной задолженности по кредитам, предоставленным субъектам малого и среднего предпринимательства, на фоне минимальных показателей роста объемов выдачи кредитов и суммы задолженности по кредитам, предоставленным этой категории предприятий, обнажает недостатки системы кредитования этого сегмента, свидетельствует о нерешенности проблемы финансирования предпринимательства, несмотря на все предпринимаемые государством меры.

На основе результатов проведенного анализа можно сформулировать ряд выводов.

1. Современная система кредитования субъектов малого и среднего предпринимательства не удовлетворяет в должной степени потребности этой категории предприятий. Об этом свидетельствуют результаты опроса руководителей малых предприятий, проводимых ежегодно Федеральной службой государственной статистики. В ходе проведенного анализа в рамках настоящей статьи были получены факты, подтверждающие результаты выше названного опроса предпринимателей.

2. В 2017-2019 гг. темпы роста объемов выдачи кредитов субъектам малого и среднего предпринимательства кредитными организациями Российской Федерации являлись наименьшими по сравнению с темпами роста аналогичных показателей по другим категориям заемщиков (юридическим лицам и индивидуальным предпринимателям без учета субъектов малого и среднего предпринимательства, а также физическим лицам). Удельный вес кредитов, предоставленных субъектам малого и среднего предпринимательства, в общем объеме выданных кредитов в анализируемом периоде имел наименьшее значение в разрезе категорий заемщиков и имел тенденцию к снижению: с 12,4\% на 01.01.2017 до 11,0\% на 01.01.2020.

3. За этот же период темпы роста задолженности по кредитам, предоставленным субъектам малого и среднего предпринимательства, имели наименьшее значение по сравнению с темпами роста задолженности других категорий заемщиков и составили за 3 года 106,0\% (если учесть уровень инфляции за этот период времени, то динамика данного показателя является отрицательной). Удельный вес задолженности по кредитам, предоставленным субъектам малого и среднего предпринимательства, в общей сумме задолженности по кредитам, выданным кредитными организациями всем категориям заемщиков, являлся наименьшим и имел тенденцию к снижению: с 11,5\% на 01.01.2017 до 9,4\% на 01.01.2020.

4. Показатель «удельный вес просроченной задолженности по кредитам в общей сумме задолженности по кредитам, предоставленным заемщикам» является одним из важнейших показателей, характеризующих не только качество 
кредитного портфеля банков, уровень кредитного риска для банков, но и в целом эффективность системы кредитования, степень ее «совершенства» и «гармоничности». Чем хуже работает система кредитования, чем менее гармонично выстроены отношения между кредитором и заемщиком, тем выше этот показатель. В результате анализа было установлено, что кредитные отношения отечественных кредитных организаций в наихудшей степени выстроены именно с заемщиками - субъектами малого и среднего предпринимательства. Так, по этой категории заемщиков в анализируемом периоде, несмотря на некоторое снижение, наблюдался наибольший удельный вес просроченной задолженности в общей сумме задолженности по кредитам: $14,2 \%$ на 01.01.2017 и 11,9\% на 01.01.2020, что практически в 2 раза превышало аналогичный совокупный показатель, рассчитанный по всем категориям заемщиков.
Таким образом, система кредитования субъектов малого и среднего предпринимательства в настоящее время не удовлетворяет потребности этого сектора экономики, имеет существенные недостатки и противоречия, что является одним из основных факторов, препятствующих развитию предпринимательства в целом. Между тем посланием Президента Российской Федерации В. Путиным Федеральному собранию были установлены целевые показатели по уровню развития малого предпринимательства к 2025 году (доля в ВВП $-40 \%$, число занятых -25 млн. человек) [3]. Достичь этих показателей без решения проблемы финансирования предпринимателей не представляется возможным, что, в свою очередь, требует скорейшего совершенствования системы кредитования малого и среднего предпринимательства за счет устранения выявленных недостатков.

\section{Библиографический список}

1. Малое и среднее предпринимательство в России - 2019 г. [Электронный ресурс]: стат. сборник // Федеральная служба государственной статистики: офиц. сайт._- Режим доступа: https://gks.ru/bgd/regl/b19_47/Main. htm [30.03.2020].

2. Сведения о размещенных и привлеченных средствах [Электронный ресурс] // Центральный банк Российской Федерации: офиц. сайт. - Режим доступа: http://www.cbr.ru/statistics/bank_sector/sors/ [30.03.2020].

3. Путин В.В. Послание президента Федеральному Собранию. 1 марта 2018 г. [Электронный ресурс] / В. В. Путин // Президент России: офиц. сайт.- Режим доступа: http://kremlin.ru/events/president/news/56957 [30.03.2020]. 